\section{Abordaje pediátrico de las infecciones de vías urinarias}

\section{Approach of Pediatric Urinary Tract Infection.}

Lombardo-Aburto $\mathrm{E}$

\section{INTRODUCCIÓN}

La infección de vías urinarias (IVUs) es la presencia de bacteriuria significativa sintomática o no, ${ }^{1}$ que se adquiere principalmente por vía ascendente, tras la colonización por gérmenes intestinales del epitelio periuretral, uretral y vesical (cistitis), pudiendo alcanzar desde el uréter hasta el tejido renal (pielonefritis); o bien, vía hematógena o directa dada por procedimientos invasivos en el tracto urinario. ${ }^{2}$

La importancia de abordar oportunamente las infecciones de vías urinarias radica en que en el 30\% de las malformaciones del riñón y tracto urinario pueden ser provocadas por IVU, que son el primer signo de alarma. ${ }^{3}$ Éstas son la causa de infección bacteriana más frecuente en niños y la causa más frecuente de fiebre sin foco en menores de 3 años. Más del 30\% de los lactantes y niños pueden presentar infecciones recurrentes durante los primeros 6-12 meses después de la primera IVU. ${ }^{4}$

Por lo anterior, el pediatra debe realizar un diagnóstico y tratamiento oportunos para evitar complicaciones como urosepsis, urolitiasis, absceso renal, cicatrices renales y, a largo plazo, con riesgo elevado de hipertensión y falla renal terminal; sin embargo, el incremento de las resistencias a los antibióticos puede retrasar el inicio de la terapia adecuada., ${ }^{3,5}$ La mayoría de las infecciones son causadas por Escherichia coli (80-90\%).

\section{EPIDEMIOLOGÍA}

La prevalencia de IVUs está influenciada por dos variables: edad y sexo. En el primer año de vida es más frecuente en niños
Médico Pediatra. Adscrito a la Consulta Externa Pediatría.

Instituto Nacional de Pediatría.

Recibido: 23 de noviembre 2017

Aceptado: 28 de noviembre 2017

Correspondencia

Lombardo-Aburto $\mathrm{E}$

elombardoaburto@yahoo.com.mx

Este artículo debe citarse como Lombardo-Aburto E. Abordaje pediátrico de las infecciones de vías urinarias. Acta Pediatr Mex. 2018;39(1):85-90. 
(3.7\%) que en niñas (2\%). Se incrementa más en lactante con fiebre, menor de 2 meses de edad, con una incidencia de $5 \%$ en niñas y $20.3 \%$ en niños no circuncidados. La incidencia se invierte en la etapa prepuberal con un $3 \%$ en niñas y $1 \%$ en niños. ${ }^{3,4}$

\section{ETIOLOGÍA}

Aproximadamente, el 95\% de las IVUs son causadas por enterobacterias. El principal patógeno en la infancia es E. coli, $90 \%$ en niñas y $80 \%$ niños, principalmente en el primer episodio de IVU. En el primer año de vida, Klebsiella pneumoniae, Enterobacter spp., Enterococcus spp. y Pseudomona spp. son más frecuentes que en otras etapas y tienen mayor riesgo de urosepsis. ${ }^{3}$

\section{CLASIFICACIÓN}

La clasificación depende del sitio de infección, episodios, síntomas y complicaciones: ${ }^{4}$

a. De acuerdo al sitio:

- Cistitis (tracto urinario bajo): inflamación de la vejiga o uretra, con síntomas miccionales y ausencia de dolor lumbar. Bajo riesgo de lesión del parénquima renal.

- Pielonefritis (tracto urinario alto): infección piógena de la pelvis y parénquima renal, con síntomas de fiebre mayor $38^{\circ} \mathrm{C}$ y alto potencial de daño renal y cicatrices corticales. Elevación de los reactantes de fase aguda.

b. De acuerdo a episodios:

- Primera infección.

- Recurrencia, que a su vez se divide en: no resuelta, persistente o reinfección.

c. De acuerdo a los síntomas

- Bacteriuria asintomática: presencia de un recuento significativo de bacterias en la orina, en ausencia de signos y síntomas clínicos.

\section{- IVU sintomática.}

\section{d. Complicaciones}

- IVU no complicada, generalmente afecta al tracto urinario bajo, morfología y función renal normal. Pacientes inmunocompetentes, mayores de 2 años, sin fiebre o fiebre menor $38^{\circ} \mathrm{C}$, síntomas miccionales, normohidratado, buen estado general y generalmente reactantes de fase aguda negativos.

- IVU complicada, en menores de 2 años, principalmente en recién nacidos con síntomas de pielonefritis, fiebre mayor $38.5^{\circ} \mathrm{C}$, tóxicos, deshidratados. Malformaciones urinarias, alteración mecánica o funcional renal y falta de respuesta al tratamiento después de 48-72 horas de haberlo iniciado.

\section{FACTORES DE RIESGO}

Existen algunas condiciones que ya se han identificado como factores de riesgo para padecer IVU en la edad pediátrica (Cuadro 1).

Cuadro 1. Factores de riesgo para infección de vías urinarias

\begin{tabular}{ll} 
Edad & Relación niño/niña \\
Recién nacidos & $4 / 1$ \\
Preescolares & $1 / 15$ \\
Escolares & $1 / 30$ \\
\hline $\begin{array}{l}\text { Predisposición } \\
\text { familiar }\end{array}$ & $\begin{array}{l}\text { Familiares de primer grado tienen } \\
\text { más riesgo de IVU. } \\
\text { Antecedentes de reflujo vésico- }\end{array}$ \\
\hline Circuncisión & En IVU recurrentes o RVU \\
\hline $\begin{array}{l}\text { Malformaciones } \\
\text { renales }\end{array}$ & $\begin{array}{l}\text { Favorecen obstrucción e IVU de } \\
\text { repetición }\end{array}$ \\
\hline Vejiga neurogénica & Mayor riesgo de IVU \\
\hline Constipación & $\begin{array}{l}\text { Mayor riesgo de IVU lactante o } \\
\text { escolar }\end{array}$ \\
\hline $\begin{array}{l}\text { Actividad sexual } \\
\text { en adolescentes }\end{array}$ & IVU de repetición \\
\hline
\end{tabular}




\section{Factores de riesgo para cicatrices renales}

Reflujo vésico-ureteral (RVU), IVU recurrentes, IVU febriles, demora en el tratamiento y malformaciones obstructivas.

\section{ABORDAJE DIAGNÓSTICO}

El punto más importante dentro del abordaje diagnóstico es realizar una historia clínica completa, haciendo énfasis en el interrogatorio sobre las siguientes consideraciones, además de la búsqueda intencionada de factores de riesgo.

1. Antecedente materno de IVU en el embarazo o ruptura prematura de membranas. ${ }^{6}$

2. Cirugías previas que requirieron colocación de sonda vesical.

3. Sitio de la infección, número de episodios, sintomatología y complicaciones.

4. Edad de inicio para control de esfínteres.

5. Ingesta de líquidos.

6. IVU bajas de repetición.

7. Retraso pondoestatural.

8. Hábitos de aseo en el área genital en mujeres.

9. Hábitos miccionales (vaciamiento urinario) e intestinales, incluidos incontinencia diurnia y nocturna, estreñimiento y encopresis.

\section{Cuadro clínico}

Las manifestaciones clínicas difieren según la edad y la localización del proceso infeccioso, según se muestra en el Cuadro 2. Otros factores también pueden influir para las manifestaciones clínicas como estado nutricional, malformaciones renales, número de eventos previos de IVUs y el intervalo entre cada episodio de infección.

Se debe realizar una exploración física completa valorando los aspectos nutricionales,
Cuadro 2. Manifestaciones clínicas por edad

\begin{tabular}{|c|c|c|}
\hline $\begin{array}{l}\text { Grupo de } \\
\text { edad }\end{array}$ & Más frecuente & $\begin{array}{c}\text { Menos } \\
\text { frecuente }\end{array}$ \\
\hline $\begin{array}{l}\text { Recién } \\
\text { nacidos y } \\
\text { lactantes } \\
\text { menor } 3 \\
\text { meses }\end{array}$ & $\begin{array}{l}\text { Urosepsis o pielonefritis: } \\
\text { vómito, fiebre o hipoter- } \\
\text { mia irritabilidad, letargia, } \\
\text { rechazo vía oral. } \\
\text { Puede haber ictericia, } \\
\text { palidéz, convulsiones }\end{array}$ & $\begin{array}{l}\text { Dolor } \\
\text { abdominal } \\
\text { Hematuria } \\
\text { Orina fétida }\end{array}$ \\
\hline $\begin{array}{l}\text { Lactantes }> \\
3 \text { meses - } 2 \\
\text { años }\end{array}$ & $\begin{array}{l}\text { Fiebre, hiporexia, falla de } \\
\text { medro, vómitos }\end{array}$ & $\begin{array}{l}\text { Dolor lumbar } \\
\text { letargia, } \\
\text { irritabilidad } \\
\text { o síntomas } \\
\text { urinarios }\end{array}$ \\
\hline $\begin{array}{l}\text { Preescolares, } \\
\text { escolares y } \\
\text { adolescentes }\end{array}$ & $\begin{array}{l}\text { Síntomas urinarios como } \\
\text { disuria, tenesmo vesical, } \\
\text { polaquiuria y orina fétida } \\
\text { o turbia, hematuria }\end{array}$ & $\begin{array}{l}\text { Fiebre, } \\
\text { irritabilidad, } \\
\text { vómitos }\end{array}$ \\
\hline
\end{tabular}

crecimiento, neurodesarrollo, estado general y signos vitales en la que no debe faltar la toma de presión arterial y fiebre sin otro foco infeccioso. ${ }^{2,3}$ La palpación abdominal en busca de masas, y si ésta se localiza suprapúbica y persiste posterior a la micción, se debe sospechar en obstrucción en el trayecto urinario, dolor lumbar y constipación. En genitales masculinos la presencia de fimosis, estenosis meato urinario, orquitis o visualizar las características del chorro urinario. En genitales femeninos la fusión de labios, cuerpo extraño, vulvovaginitis o datos sugestivos de inicio de vida sexual. En columna vertebral, región sacrococcígea, la presencia de hoyuelo sacro o quiste pilonidal. Miembros inferiores para detectar debilidad o falta de coordinación que orienten a daño neurológico..$^{2-4}$

\section{DIAGNÓSTICO}

Para establecer el diagnóstico de IVU se debe tomar en consideración el cuadro clínico y algunos parámetros de laboratorio, como son el examen general de orina, la interpretación de las tiras reactiva y el urocultivo, considerado como el "estándar de oro" para establecer el diagnóstico. 
En el examen general de orina se debe reconocer la esterasa leucocitaria, reducción de nitratos a nitritos, cuenta de células inflamatorias (más de 10 células) y presencia de bacterias. ${ }^{7}$ Se debe considerar especialmente el método de recolección de la muestra de orina, según edad y control de esfínteres, ya que los resultados puede variar en sensibilidad y especificidad según el método usado (Cuadros 3 y $\mathbf{4}$ ).

\section{Interpretación de la tira reactiva}

El uso de tiras reactivas para el diagnóstico rápido de IVU es de gran utilidad. En su interpretación se debe atender fundamentalmente a la esterasa leucocitaria y al test de nitritos. La esterasa leucocitaria es liberada por los leucocitos, siendo por lo tanto dato indirecto de inflamación en las vías urinarias, aunque no necesariamente de origen infeccioso. El test de nitritos se basa en la capacidad de las bacterias (excepto las gran positivas y pseudomonas) de reducir los nitratos a nitritos. El Cuadro 5 muestra su interpretación.

Los estudios de laboratorio como biometría hemática, química sanguínea y reactantes de fase aguda sólo son de apoyo diagnóstico y monitoreo en un paciente con IVU febril.

Cuadro 3. Recolección de orina en recién nacidos y niños sin control de esfínteres

\begin{tabular}{|c|c|c|c|}
\hline $\begin{array}{l}\text { Método de } \\
\text { recolección }\end{array}$ & Ventaja & Desventaja & Urocultivo \\
\hline $\begin{array}{l}\text { Bolsa } \\
\text { adhesiva }\end{array}$ & $\begin{array}{l}\text { No invasivo, sencillo } \\
\text { Método inicial en situaciones } \\
\text { no urgentes } \\
\text { Resultado negativo, se descarta } \\
\text { IVU }\end{array}$ & $\begin{array}{l}\text { Fácilmente se contamina } \\
\text { Falsos positivos } 75 \%\end{array}$ & $\begin{array}{l}>10,000 \text { UFC/mL de un gérmen } \\
\text { con sintomas } \\
>100,000 \text { UFC } / \mathrm{mL} \text { sin síntomas }\end{array}$ \\
\hline Cateterismo vesical & $\begin{array}{l}\text { Sensibilidad y especificidad } \\
83-99 \% \\
\text { Método de confirmación en } \\
\text { situaciones urgentes }\end{array}$ & $\begin{array}{l}\text { Invasivo, riesgo de contamina- } \\
\text { ción } \\
\text { Trauma uretral o hematuria }\end{array}$ & $>1000$ o 50,000 UFC/ML \\
\hline $\begin{array}{l}\text { Punción } \\
\text { suprapúbica }\end{array}$ & $\begin{array}{l}\text { Método de confirmación en } \\
\text { situaciones urgentes. } \\
\text { Util en niños con fimosis o } \\
\text { fusión de labios }\end{array}$ & Más invasivo & Cualquier crecimiento UFC/mL \\
\hline
\end{tabular}

Cuadro 4. Recolección de orina en niños con control de esfínteres

\begin{tabular}{|l|l|l|l|}
$\begin{array}{l}\text { Método de } \\
\text { recolección* }\end{array}$ & Ventaja & Desventaja & Urocultivo \\
\hline $\begin{array}{l}\text { Chorro } \\
\text { medio }\end{array}$ & $\begin{array}{l}\text { No invasivo, } \\
\text { sencillo. }\end{array}$ & $\begin{array}{l}\text { Fácilmente } \\
\text { se conta- } \\
\text { Método } \\
\text { mina }\end{array}$ & $\begin{array}{l}\text { 100,000 UFC/ } \\
\text { inicial en } \text { de un } \\
\text { gérmen }\end{array}$ \\
& $\begin{array}{l}\text { situaciones } \\
\text { no urgentes }\end{array}$ & \\
&
\end{tabular}

*Se debe procesar la muestra de orina a los 30-60' después de su obtención, de lo contrario refrigerarla para evitar contaminación.
Cuadro 5. Interpretación de las tiras reactivas

\begin{tabular}{|c|c|}
\hline Tira reactiva & Sospecha diagnóstica \\
\hline $\begin{array}{l}\text { Nitritos y esterasa } \\
\text { leucocitaria }(+)\end{array}$ & $\begin{array}{l}\text { IVU, sensibilidad } 80-90 \% \text {, } \\
\text { especificidad } 60-98 \% \text {, iniciar } \\
\text { tratamiento }\end{array}$ \\
\hline $\begin{array}{l}\text { Nitritos }(+) \text {, esterasa } \\
\text { leucocitaria }(-)\end{array}$ & $\begin{array}{l}\text { Prob IVU. Toma de urocultivo e } \\
\text { iniciar tratamiento }\end{array}$ \\
\hline $\begin{array}{l}\text { Nitritos }(-) \text {, esterasa } \\
\text { leucocitaria }(+)\end{array}$ & $\begin{array}{l}\text { Dudosa IVU, ver cuadro } \\
\text { clínico }\end{array}$ \\
\hline $\begin{array}{l}\text { Nitritos y esterata leu- } \\
\text { cocitaria (-) }\end{array}$ & IVU descartada \\
\hline
\end{tabular}


Imagenología

El ultrasonido renal y vesical es útil para el diagnóstico de malformaciones renales, no es útil para determinar RVU. ${ }^{8}$

Indicaciones:

- Guías NICE (guías europeas): recomiendan después del $1^{\circ}$ evento de UTI febril niños $<6$ meses o $>6$ meses con una IVU recurrente.

- APP (academia americana de pediatría): recomiendan después del $1^{\circ} \mathrm{IVU}$ febril 2-24 meses.

La cistouretrografía es el estándar de oro para diagnosticar reflujo vesicoureteral. Tiene la desventaja de ser un método invasivo, expone a los pacientes a radiación, más costoso.

Indicaciones:

- Guías NICE: recomiendan niños $<6$ meses con IVU atípica o recurrente. Niños 6-3 años con IVU atípica o recurrente. Con malformaciones renales por USG renal o historia de RVU.

- APP: recomiendan 2-24 meses después del $2^{\circ}$ IVU febril o después del $1^{\circ}$ IVU febril con malformaciones renales o RVU grave.

El DMSA se indica para el diagnóstico de cicatrices renales.

Indicaciones:

Guías NICE y APP, no lo recomiendan después del $1^{\circ}$ IVU febril de rutina.

- NICE: 4-6 meses después de IVU recurrente.

- APP: no lo incluye en sus recomendaciones.

\section{TRATAMIENTO}

Se deben considerar para la elección del antibiótico y el inicio de tratamiento la edad del paciente y el sitio de la infección (infección de vías urinarias bajas o pielonefritis). El objetivo de iniciar el tratamiento a la brevedad está dirigido a erradicar la infección y prevenir urosepsis, mejorar sintomatología, evitar cicatrices renales o absceso renal y prevenir la hipertensión e insuficiencia renal.

- IVU afebril o cistitis, el tratamiento de elección es la nitrofurantoina 5-7 mg/kg cada 6 horas o trimetroprim-sulfametozasol (TMP/SMZ) (basado en TMP) 6-12 mg/k cada 12 horas o cefalosporina de $1^{\circ} \mathrm{o} 2^{\circ}$ generación por 7-10 días, vía oral.

- IVU febril o pielonefritis, el tratamiento de elección es ampicilina más aminoglucósido o cefalosporina de $3^{\circ}$ generación durante 14 días. El tratamiento debe iniciarse por vía parenteral por tres a cinco días; debe continuar por vía oral, hasta completar diez a 14 días. El cambio de vía parenteral a oral se basa en la desaparición de la fiebre y la mejoría del estado general.

\section{Contraindicaciones:}

1. TMP/SMZ está contraindicado en prematuros y recién nacidos.

2. Nitrofurantoína está contraindicada en menores de 3 meses de edad.

\section{PROFILAXIS}

Existe controversia para el uso de antibióticos como profilaxis ante IVU. ${ }^{4}$ Las indicaciones para el uso prolongado de antibióticos como profilaxis se debe considerar en pacientes con IVU con alto riesgo de daño renal: RVU severo, pielonefritis recurrente, obstrucción del tracto urinario (megauretero, valvas uretrales). Se reco- 
miendan TMP/SMZ o nitrofurantoina, un cuarto de dosis, nocturna, diario.

Garin et $\mathrm{al}^{9}$ concluyen que no hay evidencia que dosis prolongadas en pacientes con RVU previenen cicatrices renales. Revisión Cochrane menciona que no hay evidencia que dosis bajas y prolongadas de antibiótico previenen IVU. Además, no hay apego al tratamiento y puede existir resistencia bacteriana.

\section{CONCLUSIONES}

1. El abordaje de IVU lo debe realizar el pediatría, como médico de primer contacto, y descartar en forma obligada malformaciones del tracto urinario.

2. Todo niño con fiebre sin foco infeccioso aparente, se debe sospechar en IVU, por lo que antes de prescribir un antibiótico, se debe realizar urocultivo.

3. El neonato o lactante menor de 3 meses con IVU es una urgencia que requiere hospitalización.

4. Con excepción de la etapa neonatal, la población femenina se encuentra afectada con mayor frecuencia.
5. Una vez confirmado el diagnóstico de IVU para evitar complicaciones a corto y largo plazo, se debe iniciar tratamiento antibiótico a la brevedad.

6. La mejor profilaxis para IVU es el seno materno y un diagnóstico y tratamiento oportuno.

\section{REFERENCIAS}

1. Colombiana de Salud, S.A. Guía de IVU en Pediatría, mayo 2014.

2. V. Martínez Suarez, F Santos Rodríguez. Infección de vías urinarias en el niño. Plan diangóstico-terapéutico. Bol Pediatr Esp 2006;46:222-229.

3. Simoes e Silva EA. Update on the approach of urinary tract infecion in childhood. J. Pediatr (Rio J) 2015;91:S2-10.

4. Stein R et al. Urinary Tract Infections in Children: EAU/ESPU Guidelines. Eur Urol (2014).

5. R. Beetz, M. Westerfelder. Antimicrobial therapy of urinary tract infections in children. International journal of Antimicrobial Agents 2011;38S:42-50.

6. Arshad M. et al. Urinary Tract Infections in the Infant. Clin Perinatol. 2015;42:17-28.

7. Consenso Mexicano en Infección de Vías Urinarias en Pediatr Acta Pediatr Mex 2007;28(6):289-93.

8. Copp H, Schmidt B. Work up of Pediatric Urinary Tract Infection. Urol Clin North Am. 2015;42(4):519-526.

9. Garin EH. Campos A, Homsy Y. Primary vesicoureteral reflux: review of currente concpets. Pediar Nephrol 1988;12:249-56. 